WellBeing International

WBI Studies Repository

$11-2008$

\title{
Behavioural Analysis of a Nociceptive Event in Fish: Comparisons Between Three Species Demonstrate Specific Responses
}

\author{
Siobhan C. Reilly \\ University of Liverpool \\ John P. Quinn \\ University of Liverpool \\ Andrew R. Cossins \\ University of Liverpool \\ Lynne U. Sneddon \\ University of Liverpool
}

Follow this and additional works at: https://www.wellbeingintlstudiesrepository.org/acwp_asie

Part of the Animal Studies Commons, Other Animal Sciences Commons, and the Veterinary

Physiology Commons

\section{Recommended Citation}

Reilly, S. C., Quinn, J. P., Cossins, A. R., \& Sneddon, L. U. (2008). Behavioural analysis of a nociceptive event in fish: Comparisons between three species demonstrate specific responses. Applied Animal Behaviour Science, 114(1), 248-259.

This material is brought to you for free and open access by WellBeing International. It has been accepted for inclusion by an authorized administrator of the WBI Studies Repository. For more information, please contact wbisr-info@wellbeingintl.org.

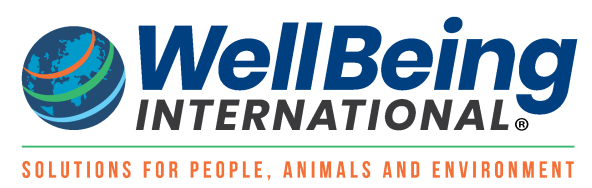




\title{
Behavioural Analysis of a Nociceptive Event in Fish: Comparisons Between Three Species Demonstrate Specific Responses
}

\author{
Siobhan C. Reilly, John P. Quinn, Andrew R. Cossins, Lynne U. Sneddon \\ University of Liverpool
}

\section{KEYWORDS}

fish, pain, nociception, welfare

\begin{abstract}
Nociception is the sensory mechanism by which potentially harmful stimuli are detected in animals and humans. The behavioural responses to noxious stimulation have been studied in two fish species thus far. However, since species-specific differences are seen in mammals, more species need to be examined to determine whether nociceptive responses are generic in fish. The present study investigated the behavioural and respiratory response to an acute noxious or potentially painful stimulus in common carp (Cyprinus carpio), zebrafish (Danio rerio) and rainbow trout (Oncorhynchus mykiss). Behavioural parameters such as frequency of swimming, use of cover and any anomalous behaviour were measured along with ventilation rate before and after noxious stimulation in the carp and zebrafish. Although no differences in behavioural or ventilation rate response were observed between noxiously stimulated carp and control fish, anomalous behaviours of rocking from side to side and rubbing of lips against the tank walls were observed in two of the five fish. In contrast, zebrafish displayed a significant reduction in frequency of swimming and an increase in ventilation rate, which was similar to the results obtained from rainbow trout. Zebrafish did not display any anomalous behaviour. These dissimilarities in response to potentially painful stimulation demonstrate that there are species-specific behavioural and physiological responses to a nociceptive event in fish.
\end{abstract}

\section{Introduction}

Fish represent a recently established model for studying nociceptive responses and have the necessary sensory components for perceiving potentially painful stimuli (Sneddon, 2002, 2003; Sneddon et al., 2003a,b). These findings have had an impact upon the treatment of fish in experimentation (Sneddon, 2006). Rainbow trout (Oncorhynchus mykiss) have a dramatically enhanced ventilation rate after a subcutaneous injection of a noxious, potentially painful substance (acetic acid) to the frontal lips (Sneddon, 2003). In the same study, prolonged behavioural responses were also observed that cannot be attributed to simple reflexes. The fish injected with acid rocked from side to side, which was suggested to be similar to stereotypical comfort behaviour in mammals (Sneddon et al., 2003a), and took approximately $3 \mathrm{~h}$ to resume feeding, compared to $1 \mathrm{~h}$ in controls, therefore, normal behaviour was suspended. When presented with a novel object, noxiously stimulated trout do not show an appropriate fear response, demonstrating that the animal's attention is dominated by the potentially painful event, 
where relatively little attention is given to the fear-causing novel object (Sneddon et al., 2003b). The behavioural reaction to nociception in goldfish (Carassius auratus) and rainbow trout (O. mykiss) changes according to circumstances (Dunlop et al., 2006). In the study conducted by Dunlop et al. (2006), electric shock stimulations were used to show that the presence of a conspecific alters the behavioural response. Plasticity to the nociceptive response has also been demonstrated in fish introduced to a novel environment (Sneddon et al., 2006). Therefore, there is the potential for pain perception in fish but so far only two species have been studied in any depth.

The fishes are one of the most diverse vertebrate groups and many species have evolved contrasting environmental tolerances to fill different niches. Our knowledge of the response to acute noxious stimuli in other species of fish is limited; however, we know that there are interspecific differences in pain responses in mammals (Lanier, 1943) as well as intraspecific variations (DeLeo and Rutkowski, 2000). With such amazing diversity in the fishes, it is vital that we test other species for their capacity for pain perception to understand if all fishes have this faculty and to develop validated behavioural criteria for the assessment of welfare.

The aim in this study is to assess the behavioural responses to a potentially painful, noxious stimulus in the common carp (Cyprinus carpio) and the zebrafish (Danio rerio) and to make comparisons with responses from rainbow trout (O. mykiss). Carp are an important commercial species in aquaculture and angling and belong to the cyprinid group, whereas rainbow trout (O. mykiss) belong to the Salmonidae group. Zebrafish are also members of the Cyprinidae and are a popular experiment model as well as an ornamental fish or pet. The response to a nociceptive stimulus is hitherto uncharacterized for carp and zebrafish. For the assessment of nociception, the criteria developed here can be used by scientists and farmers. Due to the close genetic relationship of carp and zebrafish, it is hypothesized that their behavioural responses to nociception are similar. However, if a difference in the nociceptive response is found between two such closely related species, it is feasible that differences exist between any species of fish. The behavioural response of rainbow trout has previously been characterized (Sneddon, 2003; Sneddon et al., 2003b) and they were also included in this analysis for comparative purposes, as the other two species have not been studied in such detail. Behavioural analysis will enable inferences to be made regarding the capacity of these animals to respond to a potentially harmful event and to produce reliable indicators that can be used when assessing fish welfare.

\section{Methods}

All experiments were conducted in an ethical and humane way under approval from Liverpool University's Local Ethical Committee and under Home Office (UK) licensing. Sample sizes were kept to a minimum due to the invasiveness of the procedure but we still obtained statistically significant results with these low sample sizes. Also for ethical reasons, from our pilot studies, the minimum concentrations required to produce a response were given. All fish were juveniles in order to prevent sex being a confounding factor and were reared in captive conditions, therefore were held in similar environments prior to testing.

\subsection{Zebrafish}

Zebrafish (D. rerio) of $A B$ strain were obtained from a commercial supplier. Zebrafish were held in a stock tank for 6 months at a temperature of $28^{\circ} \mathrm{C}$, a12 h:12 h light:dark cycle and were fed flake food daily (TetraMin). Only female fish identified from their relatively larger abdomens were used for experiments and were randomly selected from the stock tank (all fish: $n=16$; mean weight $=1.1 \pm 0.15 \mathrm{~g}$ ). Experimental fish were kept for 1 week in individual tanks measuring $15 \mathrm{~cm} \times 28 \mathrm{~cm} \times 11 \mathrm{~cm}$ and were visually isolated by an opaque cover. Tanks were supplied with a constant flow of filtered water in a semiclosed system and were held in conditions described above. Injections of acid were performed using a 
gastight syringe and a 34-gauge needle (Hamilton; Bonaduz, Switzerland). Fish were anaesthetised individually in a beaker $(1 \mathrm{I})$ containing $0.5 \mathrm{I}$ volume of aerated water dosed with benzocaine $(1.5 \mathrm{ml}$ of 1 $\mathrm{g} / 30 \mathrm{ml}$ ethanol).A volume of $5 \mathrm{ml}$ of $5 \%$ acetic acid was injected into each of the top and bottom frontal lips of treatment fish $(n=4)$. The same amount of saline was injected into controls $(n=4)$. Fish were placed back into their tank and left for 30 min to recover from the anaesthesia.

\subsection{Common carp}

Common carp (C. carpio) were obtained from a commercial supplier and held in a stock tank ( $2 \mathrm{~m} \times 2 \mathrm{~m} \mathrm{x}$ $0.5 \mathrm{~m}$ ) for at least 3 months. The tank was fully aerated, maintained at $20 \pm 1^{\circ} \mathrm{C}$, under a $12 \mathrm{~h}: 12 \mathrm{~h}$ light:dark regime and fed ad libitum with commercial pellets (Skretting, UK). Sixteen experimental fish (mean weight $=33.12 \pm 1.46 \mathrm{~g}$ ) were randomly chosen from the stock tank and moved to individual tanks $(50 \mathrm{~cm} \times 30 \mathrm{~cm} \times 30 \mathrm{~cm}$ ). Tanks were filled with freshwater which was continuously aerated via an airstone and airline tubing connected to a compressed air supply in a closed water system, where onethird of the water was exchanged for freshwater every 2 days and fish were held under a $12 \mathrm{~h}: 12 \mathrm{~h}$ light:dark regime. The tanks had an internal filter to assist in maintaining water quality (Interpet, Series 1 , UK). One half of the tank had an opaque cover to provide an area for sheltering and another opaque cover to visually isolate the fish from each other. They were left for 1 week to recover from possible handling stress and acclimate to the new surroundings. During this period, the fish were fed with red mosquito larvae equal to $1 \%$ body weight which results in less detritus than commercial pellets and forms part of the natural diet of carp (Rafael and Braunbeck, 1988). After 1 week, the fish were anaesthetised in a 25-I bucket containing $10 \mathrm{I}$ of aerated water dosed with benzocaine $(10 \mathrm{ml}$ of $1 \mathrm{~g} / 30 \mathrm{ml}$ ethanol). Once deep plane anaesthesia was reached, the fish were removed from the anaesthetic solution and placed on damp paper towel. The fish were divided into three groups: control $(n=6), 5 \%$ acetic acid $(n=5)$ and $10 \%$ acetic acid $(n=5)$. Sterile physiological saline $(0.9 \% \mathrm{NaCl} ; 0.1 \mathrm{ml})$ was injected subcutaneously into the upper and lower frontal lips of the fish belonging to the control group and the same volume of acetic acid $(0.1 \mathrm{ml}$ of either $10 \%$ or $5 \%$ acid, diluted in saline) was injected into the treatment groups. Acetic acid of $5 \%$ and $10 \%$ concentrations was used in the behavioural recordings for carp, and only $5 \%$ for zebrafish since carp appeared more robust or tolerant to $5 \%$ in initial experiments. The fish were returned to their home tank to recover from the anaesthesia.

\subsection{Rainbow trout}

Rainbow trout $(O$. mykiss) ( $n=12$; mean weight $=42.29 \pm 11.94 \mathrm{~g}$ ) were obtained from a commercial supplier and held in a stock tank $(2 \mathrm{~m} \times 2 \mathrm{~m} \times 0.5 \mathrm{~m})$ with a constant supply of aerated freshwater at $11 \pm$ $1^{\circ} \mathrm{C}$, on an ambient light:dark regime $(10 \mathrm{~h}: 14 \mathrm{~h})$. Fish were fed at a rate of $1.5 \%$ body weight in pellets as recommended by the manufacturer (Skretting, UK). Twelve fish were caught at random from the stock tank, transferred to individual experimental tanks $(50 \mathrm{~cm} \times 30 \mathrm{~cm} \times 30 \mathrm{~cm})$ and left for 7 days to acclimate. Each tank had a constant flow of filtered freshwater at a temperature of $11 \pm 1^{\circ} \mathrm{C}$, gravel substrate, a refuge pipe (opaque plastic, $8 \mathrm{~cm}$ length $\times 8 \mathrm{~cm}$ diameter) and some weed to mimic natural conditions. Recent work has demonstrated that trout do not show pain-related responses in barren tanks due to stress-induced analgesia (Sneddon et al., 2006). Since this project wished to examine these responses, trout had to be held under enriched conditions. Half of the top of the tank had an opaque plastic cover $(15 \mathrm{~cm} \times 30 \mathrm{~cm})$ to provide an area of shelter; the other side was left open. The sides of the tanks were covered in black plastic to visually and socially isolate the fish and prevent any disturbance. The water was continuously aerated via airline tubing and an airstone connected to an air pump.

After a 1-week acclimation period, fish in this group were individually removed from their tank and placed in a $25-\mathrm{I}$ bucket with $10 \mathrm{I}$ of anaesthetic dosed water $(1 \mathrm{ml} / \mathrm{l}$ of a $30-\mathrm{mg}$ benzocaine in $90 \mathrm{ml}$ of ethanol solution). Once deep anaesthesia was reached, the fish were carefully removed from the bucket, placed 
on wet paper towel and control fish $(n=6)$ were injected with $0.1 \mathrm{ml}$ sterile saline $(25 \mathrm{~g}$ needle and $1 \mathrm{ml}$ syringe) into the upper and lower frontal lips. Fish were then returned to their tank and allowed a 30-min recovery period from the anaesthesia and handling. The acid-treated group $(n=6)$ were treated as above but were injected into the frontal lips with $0.1 \mathrm{ml}$ acetic acid $(0.1 \%$ in sterile saline).

\subsection{Behavioural observations}

Behavioural observations were made prior to the experiment for $15 \mathrm{~min}$ and then every $30 \mathrm{~min}$ after the treatment for $15 \mathrm{~min}$. Recordings were taken for $6 \mathrm{~h}$ for carp and trout and $3 \mathrm{~h}$ for zebrafish. Behavioural observations were recorded for swim rate (a direct movement more than one body length), opercular beat rate (gill movements per minute) or ventilation rate and use of cover (percentage of time spent under cover). Anomalous behaviours were scored by observation, also during the 15-min observation period every $30 \mathrm{~min}$. For carp and zebrafish, recordings were taken by direct observation from a position which was visually isolated from the fish. Recordings of trout behaviour were taken by low light level video camera and analysed using a behavioural scoring software package. This scored duration of behaviours, frequency and events is as described before. After behavioural observations, fish were humanely killed by concussion followed by severing the spinal cord.

\subsection{Data analysis}

Data were analysed using MINITAB software. Firstly, any effect of time after the procedure was assessed in both control and treatment fish using a one-way ANOVA. Next, the values recorded before treatments were compared to the values observed after the treatment. Use of cover recordings were analysed using a Wilcoxon-matched pairs test, while the swim rate and ventilation rate data were analysed using a paired T-test.

\section{Results}

\subsection{Ventilation rate}

The zebrafish opercular beat rate significantly increased after the injection of acetic acid $(T=-4.24$; $P=0.024$; Fig. 1A), but there was no change observed after the injection of saline $(T=-0.82 ; P=0.470)$. At $30 \mathrm{~min}$, the mean opercular beat rate increased in treatment fish from the baseline value by $68.3 \%$. This increase was $88.5 \%$ at $90 \mathrm{~min}$ and $82.2 \%$ at $150 \mathrm{~min}$. The measurements taken before the procedure were not significantly different between control and treatment $\left(F_{1,6}=0.03 ; P<0.865\right)$. Time was not a significant factor in affecting opercular beat rate after the injection of acid $\left(F_{2,8}=0.18\right.$; $P=0.835)$ or saline $\left(F_{2,9}=0.44 ; \mathrm{P}=0.659\right)$.

For the opercular beat rate measurements for common carp (Fig. 1B), there was no effect of time on ventilation rate for the control group $\left(F_{5,30}=0.1 ; P=0.992\right)$, the $5 \%$ acid group $\left(F_{5,24}=0.35 ; P=0.85\right)$ or the $10 \%$ group $\left(F_{5,24}=0.42 ; P=0.831\right)$ demonstrating that the rate remained stable during the experiment for all groups. There was also no difference in ventilation rate before and after the treatment for the control group $(T=-1.45 ; P=0.206)$, the $5 \%$ acid group $(T=-0.38 ; P=0.725)$ or the $10 \%$ group $(T=-0.56 ; P=0.606)$.

The recordings of ventilation rate in rainbow trout (Fig. 1C) after the injection displayed a significant change over time in the treatment group $\left(F_{6,35}=10.54\right.$; $\left.\mathrm{P}<0.001\right)$, but not in the control group $\left(F_{6,35}=\right.$ 2.05; $P=0.08)$. The treatment group displayed a significant increase in ventilation rate $(T=-4.06$; $P<0.001)$, which was observed in the control group, but to a lesser extent $(T=-2.96 ; P=0.016)$. 
Fig. 1. Mean ( \pm S.E.) ventilation rate in $(A)$ zebrafish, $(B)$ common carp and $(C)$ rainbow trout. Ventilation rate was measured as the number of opercular movements per minute. In zebrafish $(n=4)$ and rainbow trout $(n=6)$ measurements were recorded in saline and acetic-acid-injected fish (5\% acetic acid in zebrafish and $0.1 \%$ in trout). In carp the response to $10 \%(n=6)$ acetic acid was observed in addition to control $(n=6)$ and $5 \%$ acid $(n=5)$ groups. *Significant $(P<0.05)$ in treatment zebrafish and both groups of rainbow trout when comparing ventilation rates after nociception to baseline recordings.
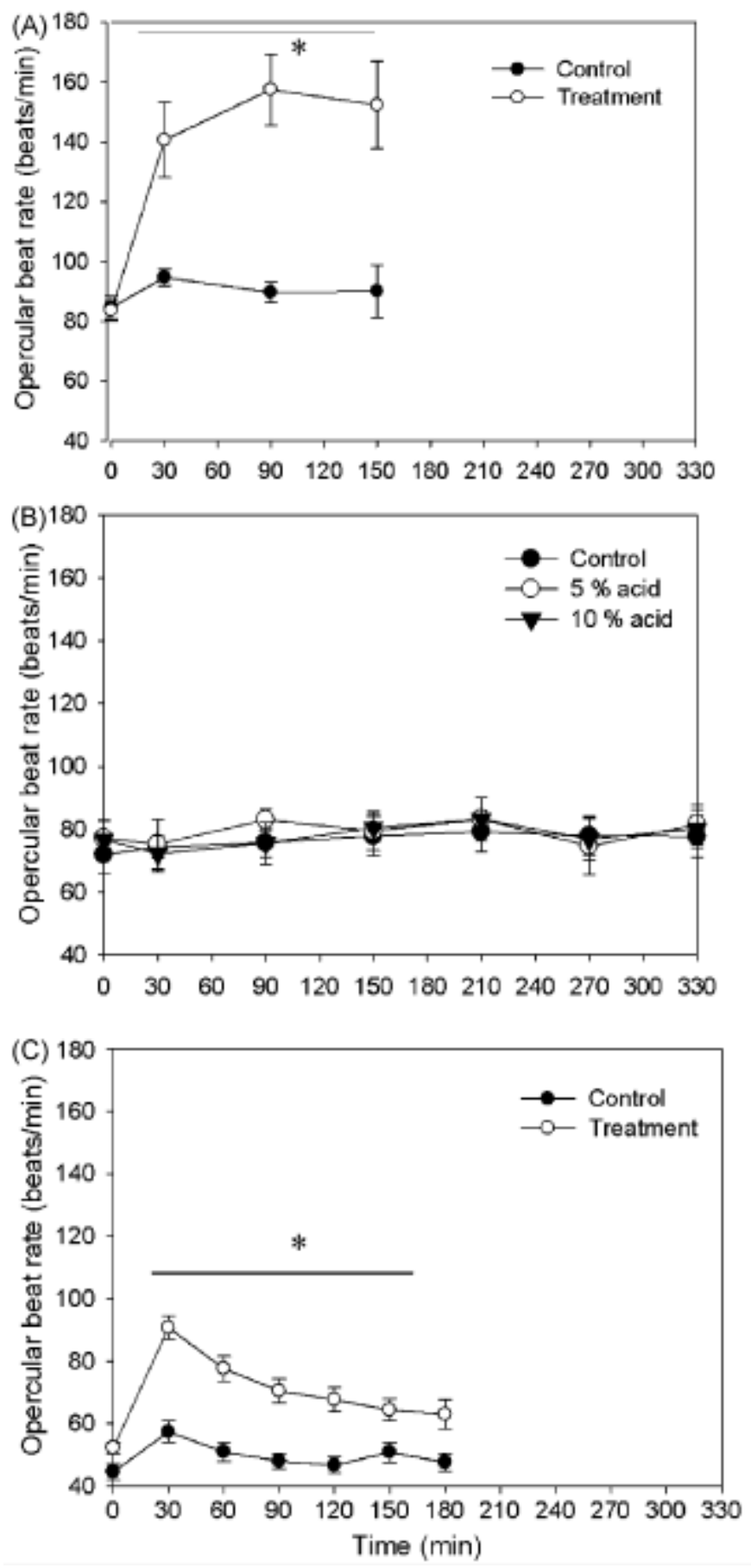
Fig. 2. Mean ( \pm S.E.) swim rate in (A) zebrafish $(n=4)$, (B) common carp $(n=5)$ and (C) rainbow trout $(n=6)$ injected with either acetic acid or sterile saline. A swim was measured when the fish swam in a continuous movement for more than one of its own length. *Significant $(P<0.05)$ in treatment fish when comparing swim rates after nociception to baseline recordings.
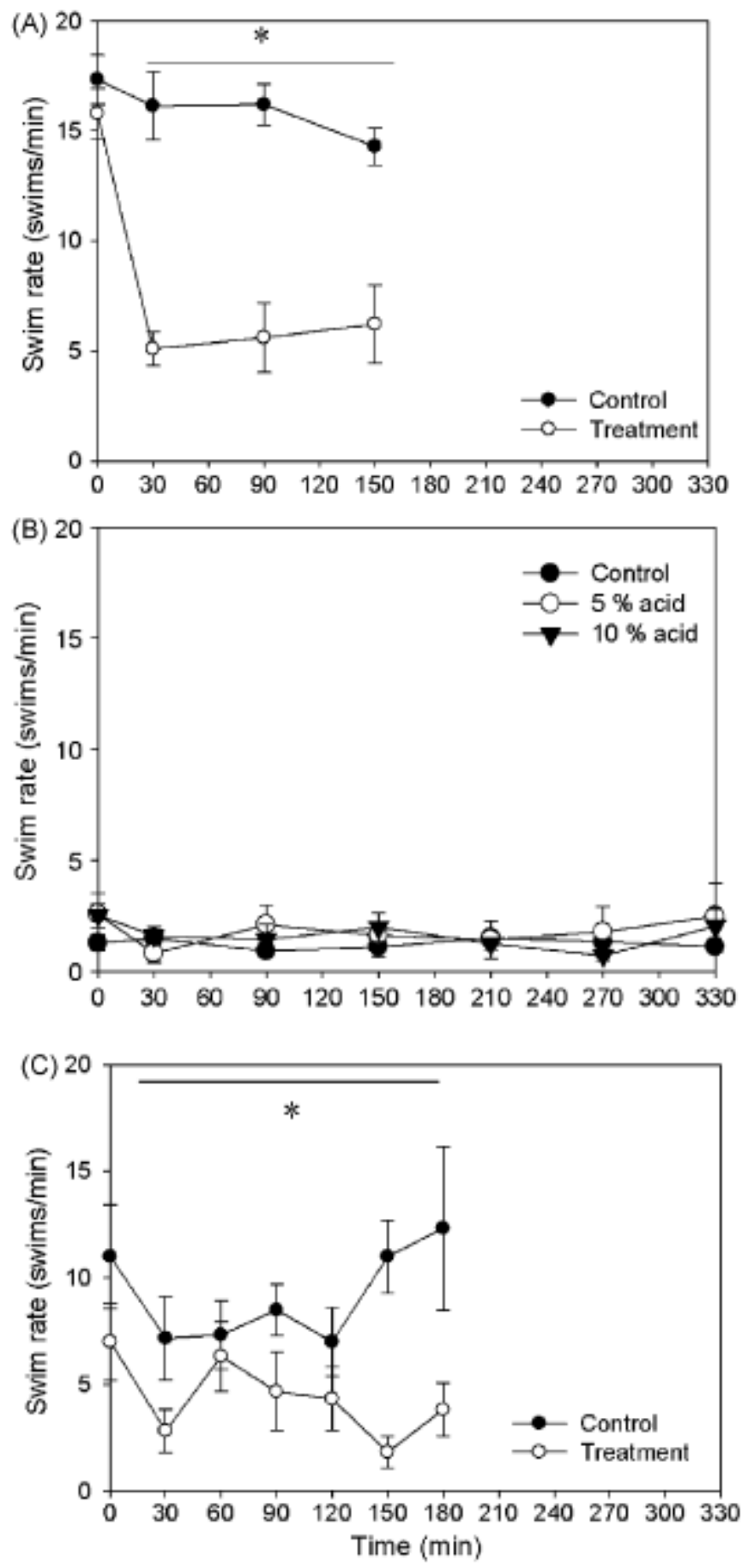


\subsection{Swim rate}

Zebrafish that were injected with acetic acid displayed a significant decrease in swim rate when compared to baseline data $(T=12.31 ; P<0.001$; Fig. $2 \mathrm{~A})$ and this was not observed in the control group ( $T=0.85 ; P=0.460)$. The largest decrease was seen at $30 \mathrm{~min}$ where the swim rate decreased by $68.3 \%$. This decrease became less pronounced as time progressed. The difference between control and treatment fish before the procedure was not significant $\left(F_{1,6}=0.73 ; P<0.426\right)$. There was no significant effect of time, after the procedure in either control $\left(F_{2,9}=0.88 ; P=0.447\right)$ or treatment $\left(F_{2,9}=0.15 ; P=\right.$ 0.862) groups.

There was no change in swimming rate (Fig. 2B) over time during the experiment in the control carp $\left(F_{5,30}=0.35 ; P=0.877\right)$, the $5 \%$ acid group $\left(F_{5,24}=0.35 ; P=0.876\right)$ or the $10 \%$ group $\left(F_{5,24}=0.86\right.$; $P=0.52)$. There was also no difference between the rates observed before and after the treatment for the control group ( $T=0.14 ; P=0.893)$, the $5 \%$ acid group $(T=1.36 ; P=0.244)$ or the $10 \%$ acid group $(T=1.46 ; P=0.219)$.

Rainbow trout in both the treatment $\left(F_{6,35}=1.29 ; P=0.289\right)$ and control $\left(F_{6,35}=1.09 ; P=0.388\right)$ groups did not alter their frequency of swimming over time after the procedure (Fig. 2C). However, when comparing baseline measurement to the values after the treatment, there was a significant decrease ( $T=3.03 ; P=0.029)$, which was not seen in the control group $(T=1.22 ; P=0.282)$.

Fig. 3. (A) Mean percentage ( \pm S.E.) of cover use in control carp $(n=6)$ and carp exposed to $5 \%(n=5)$ and $10 \%(n=$ $5)$ acetic acid injections before the injection (time $=0$ ) and at subsequent half an hour intervals. (B) Mean percentage ( \pm S.E.) of cover use in control rainbow trout $(n=6)$ and trout exposed to $5 \%$ acetic acid $(n=6)$. Nociception resulted in a significant $(P<0.05)$ increase in the use of cover in rainbow trout.
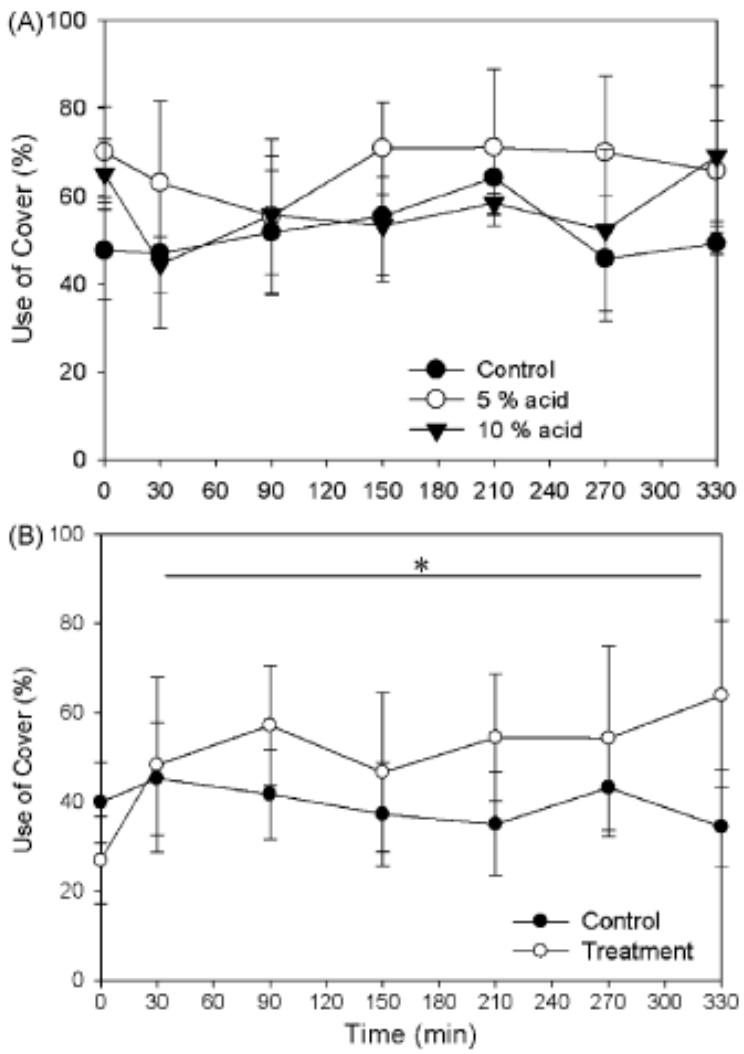


\subsection{Use of cover}

Use of cover in carp (Fig. 3A) was unaffected in relation to time in the control group $\left(F_{5,30}=0.24\right.$; $P=0.941)$, the $5 \%$ acid group $\left(F_{5,24}=0.15 ; P=0.979\right)$ and the $10 \%$ acid group $\left(F_{5,24}=0.37 ; P=0.861\right)$. There was also no significant change before and after the treatments for the control group $(W=2.0$, $P=0.052$, median change $=-19.73)$, the $5 \%$ acid group $(W=7.0, P=0.272$, median change $=-26.66)$ or the $10 \%$ acid group $(W=3.0, P=0.076$, median change $=-38.86)$.

The use of cover by rainbow trout increased after nociception (Fig. 3B). After an injection of acetic acid, there was no change over time $\left(F_{5,30}=0.13 ; P=0.983\right)$, but there was a significant change between before and after the treatment $(W=0.0, P=0.036$, median change $=-23.16)$. There was no significant change in the use of cover over time in control animals $\left(F_{5,30}=0.13 ; P=0.972\right)$ or between before and after the saline injection $(W=10.0 ; P=1.0$, median change $=-0.2461)$.

Fig. 4. Anomalous behaviours observed in carp after the injection of $10 \%$ and $5 \%$ acetic acid. These behaviours included rubbing the affected area against the walls of the tank, swimming off balance or lopsided and rocking from side to side $(n=2)$.

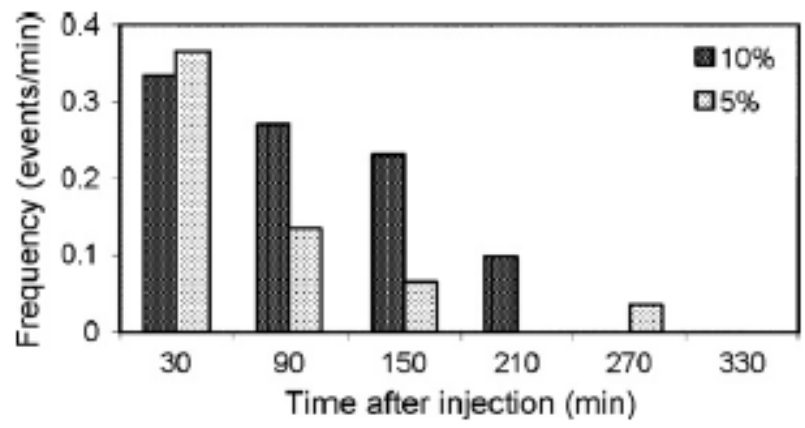

\subsection{Anomalous behaviours}

Anomalous behaviours, such as rubbing the lips against the tank walls and swimming off balance or losing equilibrium, were observed in two of the five common carp for $5 \%$ and $10 \%$ acetic acid (Fig. 4). The behaviours were most prevalent immediately after the injection, and were observed less as time progressed. Observations following acid injection showed that the rainbow trout performed anomalous behaviours after the treatment that were not seen in the saline groups: these behaviours included 'rocking' where the fishes moved from side to side balancing on either pectoral fin while resting on the gravel (mean frequency $=0.55 \pm 0.1 \mathrm{~min}^{-1}$ ). The treatment group also performed rubbing where they rubbed their lips into the gravel and against the tank walls (mean frequency $=0.56 \pm 0.2 \mathrm{~min}^{-1}$ ). There were no anomalous behaviours recorded after the procedure in zebrafish.

\section{Discussion}

The increased ventilation rate and decreased activity observed in this study demonstrated that a physiological and behavioural response was elicited by a potentially painful stimulus in zebrafish and trout. These responses were not seen in carp, indicating that the response to a nociceptive stimulus is species-specific. Zebrafish and trout that were exposed to a noxious event were significantly less active than control fish indicating a reduction in normal behaviour. Altered activity is an important behavioural measurement and can be used to indicate poor welfare (Kristiansen et al., 2004). The decreased swim 
rate after the injection of acetic acid is similar to the immobile state witnessed in other animals subject to noxious stimulation (e.g. chickens, Gentle, 1992). There are many examples of higher vertebrates becoming less active and interacting less with their environment when they are experiencing pain, for example farm animals immediately after castration (Molony and Kent, 1997). This response may perform the function of protecting the animal from a predator when injured by making them less conspicuous or conserving energy demands in case a fight or flight response is required. However, reduced activity after the treatment was not seen in common carp. Common carp are incredibly robust fish and can tolerate temperatures between 0 and $30^{\circ} \mathrm{C}$ and can also withstand prolonged hypoxia (Zhou et al., 2000). In contrast, rainbow trout are a cold water temperate species that are generally considered to be hypoxiaintolerant (Gamperl et al., 2001) and zebrafish are a tropical species that inhabit waters between 22 and $30^{\circ} \mathrm{C}$ and are also intolerant to low oxygen (Rees et al., 2001). This may explain why carp are relatively insensitive to low concentrations of acid, as they are better able to maintain homeostasis relative to trout and zebrafish.

Changes in opercular beat rate of zebrafish and trout in the treatment groups compared to the controls were dramatic. Opercular beat rate is a well-established method for measuring acute stress in fish and has been used in many studies to assess fish welfare (Johnston et al., 1994; Sneddon, 2003; Brown et al., 2005). When a fish is experiencing stress, its rate of respiration increases and the heightened oxygen demand is quantifiable by measuring the rate at which the gills are irrigated. Fish that are stressed by confinement show increased ventilation rate, which is correlated to an increase in plasma cortisol levels in some studies (Barreto and Volpato, 2004). Therefore, this result indicates that zebrafish are stressed for at least $3 \mathrm{~h}$ after an acute nociceptive insult. The increased opercular beat rate in zebrafish and trout after a nociceptive stimulus is mirrored in higher vertebrates with a heightened respiratory and cardiovascular response (Kato et al., 2001). Again carp did not show this rise in ventilatory rate.

In the carp, a nociceptive stimulus did not elicit an alteration in normal behaviour or ventilation. These different responses to nociception reflect a species-specific difference even though carp and zebrafish are closely related. Four inbred strains of the paradise fish (Macropodus opercularis) showed differing passive avoidance learning responses after a mild electric shock punishment (Csanyi and Gervai, 1986), indicating that the precise behavioural response to aversive stimuli can have a strong genetic component. Indeed, some commentators have warned of the danger of extrapolating results from different taxa when concerned with issues of fish welfare (Huntingford et al., 2006). A species-specific nociceptive difference between the Salmonidae and Cyprinidae fish groups has previously been discovered. Trout (O. mykiss) are more willing to endure electric shocks to stay in the vicinity of a conspecific than goldfish (C. auratus) (Dunlop et al., 2006). The results from the present study highlight the importance of using different parameters to assess fish welfare and this should be dependent upon species. For example, ventilation rate and activity levels may be valid indicators of suffering or poor welfare in rainbow trout and zebrafish. However, the present study shows that it is not appropriate to use these measurements to make inferences about the common carp. Common carp demonstrated robustness or increased tolerance to noxious stimulation and, therefore, it is vital that we assess nociception in fish not only on a species by species basis, but also with an assessment of different strains as has been done in mice (Kerr and David, 2007).

Sneddon (2003) observed complicated anomalous behaviours in the rainbow trout during the period following a nociceptive event. In two of the five carp injected with $5 \%$ and $10 \%$ acetic acid, the same anomalous behaviours were observed. The behaviours performed by carp and trout include rocking from side to side, swimming off balance and rubbing lips against the walls of the tank. The fact that only two out of five carp in each group exhibited these behaviours may be because of different phenotypes between individuals of the same species. Rainbow trout stressed with resident-intruder tests and 
unfamiliar environments show either a proactive or reactive response (Schjolden et al., 2005); here the differing behavioural traits are consistent in individuals across different situations. A similar phenomenon may be happening in the present study, where fish exposed to the same situation express two phenotypes, one where anomalous behaviours are exhibited and the other which is passive. Further work could determine whether these individual differences correlate to proactive and reactive stress responses. The observed individual differences may also be due to plasticity in response to pain (Sneddon et al., 2006). This plasticity could complicate comparisons between species as two individuals of different species may behave in a more similar way if they have been exposed to the same environmental stressors. However this effect has been somewhat minimized by rearing all fish in captive conditions. Therefore, it is important to take into account these individual differences in future studies when considering welfare and indicators of wellbeing.

The anomalous behaviours in carp were mainly performed in the first observation following the injection of the noxious stimulus. The frequency of these behaviours decreased steadily as time progressed, to the point where they were eliminated at $270 \mathrm{~min}$. This transient effect was also seen in the reduced activity of zebrafish, where the decreased swim rates were most pronounced in the observations directly following the injection. Pain and the resulting pain-related activity are most intense at the onset (Molony et al., 1993) and behavioural studies of mammals have shown that the increase in respiration in clinical studies of pain becomes habituated in sustained pain (Kato et al., 2001).

When making assessments of pain in animals, it is also important to consider that the behaviour is likely to be stimulus-specific. Previous guidelines for assessing distress in fish have noted that in response to severe, chronic wounds, fish may appear to behave relatively normally and can continue activities such as feeding. In contrast, acute stimuli such as exposure to a strongly acidic environment may cause the animal to increase opercular movements, attempt to jump from the water and show abnormal swimming behaviour (http://www.newcastle.edu.au/research/animal/docs/acec16.pdf, The University of Newcastle, Australia, 1993). The present study tested only one kind of noxious stimulation applied to the lips and it is possible that other stimuli or damaged body areas may give rise to different responses. In rainbow trout, bee venom did produce rocking behaviour but rubbing of the lips was not seen (Sneddon et al., 2003a).

\section{Conclusion}

The behavioural evidence in common carp contrasts with the results from zebrafish and rainbow trout; therefore, indicators should be developed that are species-specific by examining a variety of fish species. It is vital that we know how invasive practices affect fish welfare and reliable indicators of welfare are necessary in order to assess wellbeing on farm, in the field and in the aquarium. Behavioural indicators of nociception in fish should be further developed in light of the species-specific responses to nociception that were demonstrated in this study. Determining whether a fish is experiencing nociception is complicated by intraspecific differences. For example, in common carp only two of the five fish tested displayed anomalous behaviours of rocking and rubbing. Therefore, these behaviours on their own could not be used as criteria for nociception in carp.

\section{Acknowledgements}

This work was funded by a BBSRC Committee Ph.D. Studentship awarded to SCR and a BBSRC Research Grant awarded to LS.We are grateful to Gregor Govan for technical assistance. 


\section{References}

Barreto, R.E., Volpato, G.L., 2004. Caution for using ventilatory frequency as an indicator of stress in fish. Behav. Process. 66, 43-51.

Brown, C., Gardner, C., Braithwaite, V.A., 2005. Differential stress responses in fish from areas of highand low-predation pressure. J. Comp. Physiol. B: Biochem. Syst. Environ. Physiol. 175, 305-312.

Csanyi, V., Gervai, J., 1986. Behavior-genetic analysis of the paradise fish Macropodus opercularis. II. Passive avoidance learning in inbred strains. Behav. Genet. 16, 553-557.

DeLeo, J.A., Rutkowski, M.D., 2000. Gender differences in rat neuropathic pain sensitivity is dependent on strain. Neurosci. Lett. 282, 197-199.

Dunlop, R., Millsopp, S., Laming, P., 2006. Avoidance learning in goldfish (Carassius auratus) and trout (Oncorhynchus mykiss) and implications for pain perception. Appl. Anim. Behav. Sci. 97, 255271.

Gamperl, A.K., Todgham, A.E., Parkhouse, W.S., Dill, R., Farrell, A.P., 2001. Recovery of trout myocardial function following anoxia: preconditioning in a non-mammalian model. Am. J. Physiol. Regul. Integr. Comp. Physiol. 281, 1755-1763.

Gentle, M.J., 1992. Pain in birds. Anim. Welf. 1, 235-247.

Huntingford, F.A., Adams, C., Braithwaite, V.A., Kadri, S., Pottinger, T.G., Sandoe, P., Turnbull, J.F., 2006. Current issues in fish welfare. J. Fish Biol. 68, 332-372.

Johnston, N.A.L., Campagna, V.S., Hawkins, P.R., Banens, R.J., 1994. Response of the eastern rainbowfish (Melanotaenia duboulayi) to toxic Microcystis aeruginosa. Aust. J. Mar. Fresh Res. 45 (5), 917-923.

Kato, Y., Kowalski, C.J., Stohler, C.S., 2001. Habituation of the early pain-specific respiratory response in sustained pain. Pain 91, 57-63.

Kerr, B.J., David, S., 2007. Pain behaviors after spinal cord contusion injury in two commonly used mouse strains. Exp. Neurol. 206 (2), 240-247.

Kristiansen, T.S., Ferno, A., Holm, J.C., Privitera, L., Bakke, S., Fosseidengen, J.E., 2004. Swimming behaviour as an indicator of low growth rate and impaired welfare in Atlantic halibut (Hippoglossus hippoglossus L.) reared at three stocking densities. Aquaculture 230, 137-151.

Lanier, L.H., 1943. Variability in the pain threshold. Science 97, 49-50.

Molony, V., Kent, J.E., Robertson, I.S., 1993. Behavioural response of lambs of three ages in the first three hours after three methods of castration and tail docking. Res. Vet. Sci. 55, 236-245.

Molony, V., Kent, J.E., 1997. Assessment of acute pain in farm animals using behavioral and physiological measurements. J. Anim. Sci. 75, 266-272.

Rafael, J., Braunbeck, T., 1988. Interacting effects of diet and environmental temperature on biochemical parameters in the liver of Leuciscus idus melanotus (Cyprinidae: Teleostei). Fish Physiol. Biochem. 5 (1), 9-19. 
Rees, B.B., Sudradjat, F.A., Love, J.W., 2001. Acclimation to hypoxia increases survival time of zebrafish, Danio rerio, during lethal hypoxia. J. Exp. Zool. 289 (4), 266-272.

Schjolden, J., Stoskhus, A.,Winberg, S., 2005. Does individual variation in stress responses and agonistic behavior reflect divergent stress coping strategies in juvenile rainbow trout? Physiol. Biochem. Zool. 78, 715-723.

Sneddon, L.U., 2002. Anatomical and electrophysiological analysis of the trigeminal nerve in a teleost fish, Oncorhynchus mykiss. Neurosci. Lett. 319, 167-171.

Sneddon, L.U., 2003. The evidence for pain in fish: the use of morphine as an analgesic. Appl. Anim. Behav. Sci. 83, 153-162.

Sneddon, L.U., Braithwaite, V.A., Gentle, M.J., 2003a. Do fishes have nociceptors? Evidence for the evolution of a vertebrate sensory system. Proc. Biol. Sci. 270, 1115-1121.

Sneddon, L.U., Braithwaite, V.A., Gentle, M.J., 2003b. Novel object test: examining nociception and fear in the rainbow trout. J. Pain 4, 431-440.

Sneddon, L.U., 2006. Ethics and welfare: pain perception in fish. Bull. Eur. Assoc. Fish Pathol. 26, 7-11.

Sneddon, L.U., Ashley, P.J., Edwards, K.L., Winrow-Giffin, A., McCrohan, C.R., 2006. Using selective attention strategies to understand the importance of the subjective "painful" experience in fish. In: Mendl, M., Bradshaw, J.W.S., Burman, O.H.P., Butterworth, A., Harris, M.J., Held, S.D.E., Jones, S.M., Littin, K.E., Main, D.C.J., Nicol, C.J., Parker, R.M.A., Paul, E.S., Richards, G., Sherwin, C.M., Statham, P.T.E., Toscano, M.J., Warriss, P.D. (Eds.), Proceedings of the 40th International Congress of the ISAE, Bristol, August 8-12, 2006, p. 113.

Zhou, B.S.,Wu, R.S.S., Randall, D.J., Lam, P.K.S., Ip, Y.K., Chew, S.F., 2000. Metabolic adjustments in the common carp during prolonged hypoxia. J. Fish Biol. 57 (5), 1160-1171. 